Coryphoid Thrinax is said to have six to twelve stamens". Thrinax, when limited in concept, usually has flowers with six stamens, but the segregate genera Coccothrinax and Zombia usually have more than six stamens as an examination of descriptions or specimens will definitely show. The author does raise provocative questions about the androecium which are not yet definitively answered.

Three chapters on generic notes deal with selected genera but without any explanation of the basis for selection. Professor Corner disclaims in his preface any intent to provide a book which is systematic or taxonomic. It is regrettable, however, that he did not take some stand on the genera allied (or some of them, at least) to Cocos which in the unreliable Appendix B is listed as monotypic, for he gives the impression of a larger genus. This ambivalence is not comforting to the reader. The chapters do not contain useful comparative descriptions but instead comprise a series of miscellaneous jottings including paragraphs on how to climb palms. They, with the sketchy and not always correct characterizations of the family and sub-families in a chapter on classification, as well as careless keys in the fifteenth chapter and Appendix A, might well have been omitted.

Appendix A consists of keys to the "commoner" fan palms and pinnate-leafed palms. What a "commoner" palm might be is nowh re stated. The keys serve best as examples of what to avoid: for example, the couplet (7, page 352) "tropical" versus "temperate" to separate the American Acoelorrhaphe from Chamaerops and Trachycarpus in the Old World. The last two are distinguished from each other in the succeeding couplet by "leaf-stalk strongly spiny" versus "slightly spiny". Chamaerops, however, is more readily distinguished by the orientation of the longer marginal teeth on the petiole in the vegetative state. Chamaedorea elatior, sometimes cultivated, keys to Desmoncus in the couplet "climbing" versus "not climbing" (6, page 354). Euterpe precatoria, one of the most abundant and widespread American palms, keys to the Old World genus Rhopaloblaste because of its pendulous pinnae. Perhaps the flowers (and fruits) which provide characteristics leading to accurate identification are not so mean after all.

Where Professor Corner has worked from first-hand observation, as in his description of the development and fall of leaves in Actinorhytis calapparia (page 43), he has made a distinct contribution. I can only agree with him when he writes that "Palms must be studied in their immensity in nature. They cannot be deduced in a metropolis.... The hugeness of palms restores the lesson, so easily forgotten, that biological classification deals not with figment but with living things which were before man". Perhaps it is not only the hugeness of the plants but of the scope and complexity of detail to be considered that has defeated a bold and at least thought-provoking attempt to reduce the essential nature of palms to words.

Haroun E. Moore, Jun.

\section{FUNGI WITHOUT WALLS}

\section{The Cellular Slime Molds}

By John Tyler Bonner. Second edition, revised and aug. mented. Pp. $x+205$. (Princeton, N.J.: Princeton University Press; London: Oxford University Press, 1967.) $60 s$.

The description of this second edition as a revised and augmented version of the first edition needs some amplification, particularly because my review of the first edition was somewhat severe (Nature, 184, 1976; 1959). In the eight years since the first edition a substantial amount of pertinent and detailed experimental investigation has been carried out on the Acrasiales. The number of refer- ences cited in the first edition (up to 1959) was 124, and this included the older descriptive work from 1902 onwards as well as the newer experimental work starting with Raper about 1936. This second edition contains 341 references; a marked increase in a relatively short period, and one which reflects a considerable increase in interest in the group.

Dr Bonner gives his prime interest in writing the book as its usefulness for future experimental research. This edition should help considerably in that direction, for it reviews all the published work that is significant and relevant. Dr Bonner has probably had to compromise between comprehensiveness and reasonable size, but he includes the implications of the different approaches that have been made. These include cell biology, biochemistry, fine structure, physiology, developmental studies and taxonomy. In some connexions the discussion is tantalizingly short. For example, more could easily have been written about the control of orientation in the growth of the sorocarp away from the substratum, but within the space he has used for the book Dr Bonner has hit a good balance between the various aspects. Interest is stimulated, and references to the original work are given and can be followed up.

More than half of the book has been completely rewritten for this edition. The first two chapters, which present a perspective of the Mycetozoa one group with another, and describe the better known members of the Acrasiales, are little changed. There is some additional material where necessary, as in the inclusion of the Protosteliales, and in the fuller description of the species of Dictyostelium. The remaining two chapters of the first edition have been expanded to three chapters, and follow the logic which the author has elsewhere established, by separately discussing the three phases of development, which are growth, morphogenetic movement, and differentiation. As he has stated before, these three phases are very clearly demarcated in the Acrasiales, and this is one of their advantages as material for the study of development, permitting individual and separate analyses of each phase.

The short chapter on growth includes some useful detail on laboratory methods, although I feel that it would have been helpful to have given more in a book with the stated aim of this one. A description of methods of isolation and some discussion of the natural history of the organisms (the outstanding omission of the book) would have been particularly appropriate. I wonder also whether some suggestions for class experiments with Dictyostelium might not have been worth while. The organisms are fascinating for this purpose and an introduction to them at an early stage might serve to recruit more contributors to future research.

The remaining two chapters comprise the best of the book. A good deal of the work that has been done with these organisms still does not allow of very firm conclusions, and may be interpreted in more than one way. The author seems to me to be very fair in his discussion and evaluation of the evidence. He is also generous in his consideration of the contributions of the different workers in the field. Where work is inconclusive he points this out, and points the way, often with reasonable suggestions, in which research might be directed. One of the attractive features of this book is the way in which research problems and points of uncertainty are given special attention. I found this part a great improvement on the corresponding part in the first edition. The quality of photographic reproduction is poor; much worse than in the first edition.

While the book is rather short, particularly in view of its price, $I$ think the author, in maintaining the interest at a high level and in permitting the several aspects of research to be seen in proximity and in perspective, has produced a book which should fulfil his aim. More than ever, I find these creatures of absorbing interest.

David Park 